\title{
Lacan e a experiência mística à luz da psicanálise ${ }^{* 1}$
}

\section{Lacan and the mystical experience in the light of psychoanalysis}

\author{
Denise Maurano*2 \\ Bruno Albuquerque*3
}

\begin{abstract}
O presente artigo apresenta como Jacques Lacan inangura uma nova maneira de abordar a experiência mística à luz da psicanálise. Contrapondo-se a tendências no campo da psicologia, da psiquiatria e da psicanálise de patologizar esse fenômeno, reduzindo-o à sintomatologia histérica ou psicótica, o mestre francês aproximou o percurso do analista daquele empreendido pelo místico, traçando uma intima conexão entre o fim da análise e a conquista de uma abertura para o campo do feminino. Nas trilhas abertas por esse autor, propomos diferenciar as noções de gozo Outro e gozo do Outro, indicando elementos para um diagnóstico diferencial entre experiência mística (marcada pela dessubjetivação) e surto psicótico (marcado pelo aniquilamento subjetivo).
\end{abstract}

Palavras-chave: Jacques Lacan, experiência mística, psicanálise, gozo

${ }^{* 1} \mathrm{O}$ presente artigo consiste em uma versão consideravelmente revista e ampliada de uma comunicação intitulada "A experiência mística, mais além da fantasia", apresentada em 2017, no VII Encontro Nacional e VII Colóquio Internacional do Corpo Freudiano Escola de Psicanálise - Uma janela para o Real: a fantasia na psicanálise, em São Luís (MA), e de uma palestra intitulada "Lacan e a mística", apresentada em 2018, no III Seminário Apophatiké: Estudos Interdisciplinares em Mística, na Pontifícia Universidade Católica do Rio de Janeiro (RJ).

*2 Universidade Federal do Estado do Rio de Janeiro - Unirio (Rio de Janeiro, RJ, Brasil)

${ }^{* 3}$ Universidade Federal de Juiz de Fora - UFJF (Juiz de Fora, MG, Brasil). 


\section{Introdução}

Muitas aproximações foram feitas ao tema da experiência mística a partir da psicologia, da psiquiatria e da psicanálise. Os teóricos da mística distinguem os fenômenos místicos propriamente ditos daqueles chamados paramísticos, com os quais frequentemente são confundidos e que, não obstante, são olhados com suspeita tanto por clínicos e teóricos do psiquismo quanto pelos mestres espirituais, que advertem a respeito dos frequentes enganos que produzem. William James (1902/1995) inaugurou o campo da psicologia da religião com a obra As variedades da experiência religiosa, na qual propõe como características da mística a inefabilidade, a iluminação intelectiva, a passividade e a transitoriedade.

Sigmund Freud abordou o fenômeno da mística no diálogo com o escritor Romain Rolland sobre o sentimento oceânico em "O mal-estar na cultura" (Freud, 1930[1929]/1996e), construindo hipóteses para sua origem a partir da fusão e separação entre o Eu e o mundo externo. Tal diálogo deve ter produzido efeitos consideráveis no mestre vienense, posto que há uma referência à mística entre suas últimas anotações, na qual a situa como obscura autopercepção do Eu sobre o Isso (Freud, 1941[1938]/1996f).

Nas trilhas abertas por ele, outros autores procuraram se aproximar do tema. Na obra Experiência mística e psicanálise, Ricardo Torri de Araújo (2015) define a experiência mística como uma "vivência de ultrapassagem dos limites do eu acompanhada do sentimento gozoso de comunhão com o todo circundante identificado ao divino" (p. 10). Carlos Domínguez Morano (2016) propõe abordá-la como uma "vivência de vinculação amorosa e 


\section{ARTIGOS}

gozosa com aquilo que se considera a origem da existência" (p. 13; tradução nossa).

No conjunto das obras dedicadas à abordagem psicanalítica da mística, merece destaque o livro de Marlos Terêncio (2011) intitulado Um percurso psicanalítico pela mística, de Freud a Lacan, no qual o autor apresenta de modo consistente o tema nas obras freudiana e lacaniana, traçando articulações interessantes com muitos conceitos fundamentais para a psicanálise, tais como amor e sublimação, estruturas clínicas, o campo do gozo e os registros Real, Simbólico e Imaginário.

\section{Linguagens místicas e abordagens críticas}

Conforme indica Araújo (2015), são duas as principais metáforas da linguagem mística que comparecem na tradição judaico-cristã para referir-se ao encontro entre a humanidade e a divindade: o encontro nupcial entre o homem e a mulher e o acalento experimentado pelo bebê no colo da mãe. ${ }^{1} \mathrm{~A}$ tradição bíblica faz uso recorrente dessas metáforas para descrever a relação entre $\mathrm{YHWH}^{2}$ e o povo de Israel.

Na Bíblia Hebraica, desde o livro de Oseias, o amor de Deus pelo povo é simbolizado pelo amor entre marido e mulher: "Por isso, eis que, eu mesmo, a seduzirei, conduzi-la-ei ao deserto e falar-lhe ei ao coração [...] Eu te desposarei a mim para sempre [...] no amor e na ternura. Eu te desposarei a mim na fidelidade e conhecerás a YHWH" (Bíblia, 2010, p. 1586-1587; Os 2, 16.21-22). O ápice dessa linguagem pode ser encontrado no livro do Cântico dos Cânticos, onde o amado e a amada entoam poemas apaixonados: "Meu amado é meu e eu sou dele" (Bíblia, 2010, p. 1092; Ct 2,16). No Saltério, Israel também

${ }^{1}$ Retomamos nesta seção alguns elementos trabalhados na resenha "Mística e psicanálise: uma introdução, de Freud a Lacan" (Albuquerque, 2018), aos quais foram feitos acréscimos substanciais. Cf. também o verbete "Mística e psicanálise" da Enciclopédia Digital Theologica Latinoamericana (Araújo, s/d).

${ }^{2}$ Como observa a psicanalista Betty Fuks em seu estudo Freud e a judeidade, YHWH é o "tetragrama impronunciável que designa o nome do Deus invisível e irrepresentável do povo judeu" (Fuks, 2000, p. 169). Optamos por manter o tetragrama YHWH em vez da forma "Iahweh", adotada na versão consultada da Bíblia. 
é comparado a uma criança que repousa no colo materno, "como criança desmamada no colo de sua mãe" (Bíblia, 2010, p. 1003; Sl 131/130, 2).

A Bíblia Cristã retoma tanto a imagem nupcial quanto a imagem materna. Jesus faz uso da linguagem matrimonial, especialmente na parábola do banquete nupcial, na qual encontramos esta metáfora: "O Reino dos Céus é semelhante a um rei que celebrou as núpcias do seu filho" (Bíblia, 2010, p. 1743; Mt 22,2). Outra metáfora pode ser encontrada na parábola das virgens prudentes: "Então o Reino dos Céus será semelhante a dez virgens que, tomando suas lâmpadas, saíram ao encontro do noivo" (Bíblia, 2010, p. 1749; Mt 25,1). Lamentando a recusa de Jerusalém em acolher a mensagem dos profetas e a sua própria, o Nazareno interpreta sua atuação com traços maternais, "como a galinha recolhe seus pintinhos debaixo das asas" (Bíblia, 2010, p. 1746; Mt 23,37).

Nos escritos paulinos, Paulo comparará o amor nupcial ao amor de Cristo pela Igreja: "E vós maridos, amai vossas mulheres, como Cristo amou a Igreja e se entregou por ela" (Bíblia, 2010, p. 2046; Ef 5,25). Nos escritos joaninos, o livro do Apocalipse se refere às "núpcias do Cordeiro" (Bíblia, 2010, p. 2162; Ap 19,7) e narra uma visão da resplandecente Jerusalém 442 celeste: "Vi também descer do céu, de junto de Deus, a Cidade santa, uma Jerusalém nova, pronta como uma esposa que se enfeitou para seu marido" (Bíblia, 2010, p. 2165; Ap 21,2).

Seguindo a espiritualidade bíblica, os místicos da tradição cristã frequentemente recorrem ao simbolismo matrimonial para tentar transcrever em palavras suas experiências, sem nunca deixar de ressaltar os limites da linguagem, que é sempre aproximativa. Santa Teresa d'Ávila (2016) expressa sua entrega confiante e amorosa a Deus em belos versos poéticos: "Já toda me entreguei e dei, / E de tal modo mudei, / Que meu amado é para mim / E eu sou para meu amado" (p. 228). São João da Cruz (2013) escreve no gênero feminino a experiência da alma que busca a união de amor com Deus: "Esquecida, quedei-me, / O rosto inclinado sobre o Amado; / Tudo cessou. Deixei-me, / Largando meu cuidado / Por entre as açucenas olvidado" (p. 22).

Lacan (1972-73/2008b) atribui alto valor aos escritos dos místicos e chega até mesmo a incluir seu próprio nome entre eles, como que insinuando uma aproximação entre o místico e o psicanalista: "Essas jaculações místicas, não é lorota nem só falação, é em suma o que se pode ler de melhor — podem pôr em rodapé, nota - Acrescentar os Escritos de Jacques Lacan, porque é da mesma ordem" (p. 82; grifo no original). 


\section{ARTIGOS}

A despeito do alto valor poético e religioso da escrita mística, reconhecido pelo campo da cultura, ela foi duramente criticada no campo da psiquiatria, da psicologia e da psicanálise, questionando-se sua autenticidade e a saúde mental do sujeito que narra essa experiência. Seu caráter erótico levantou a suspeita de que a mística seria uma forma substitutiva e neurótica de satisfação sexual, ${ }^{3}$ configurando-se como um sintoma histérico. No campo da medicina, chegou-se a atribuir a Santa Teresa d'Ávila o irônico título de "padroeira da histeria", conforme relatado em "Estudos sobre a histeria" (Freud \& Breuer 1893-1895/1996, p. 251). De fato, as abordagens científicas do psiquismo mostraram que a erotização da relação amorosa com a divindade pode estar atrelada a uma perturbação da devoção religiosa. ${ }^{4}$ Entretanto, isto não implica que toda experiência mística se configure necessariamente como um sintoma histérico.

Três reações distintas foram propostas à interpretação da mística em referência à esfera da sexualidade. William James (1902/1995) entende que o vocabulário erótico, nupcial e amoroso dos místicos é usado em sentido metafórico, porque suas vivências extrapolam os limites da linguagem. Antoine Vergote (1978), por outro lado, admite a natureza sexual da experiência mística, mas recusa a ideia de que essa dimensão libidinal autorize sua desqualificação, pois considera que a sexualidade é a condição de possibilidade humana para a mística. Lacan (1972-73/2008b), por sua vez, sustenta que a experiência mística ultrapassa o campo da linguagem e da sexualidade, apontando para um gozo mais além ou aquém do fálico, a despeito da castração simbólica — a qual, entretanto, é considerada um pressuposto necessário. Portanto, ele interpreta a imagem conjugal utilizada

${ }^{3}$ Dentre os autores que sustentaram esta posição, cabe destacar James Leuba, Pierre Janet, Joseph Breuer, Wilhelm Reich, Marie Bonaparte, Herbert Moller e Guillaume Han (cf. Araújo, 2015).

${ }^{4}$ Este parece ter sido o caso do Conde Zinzendorf, um dos pais do pietismo que teve sua obra analisada pelo pastor e psicanalista Oskar Pfister (1910), que se correspondeu com Freud durante aproximadamente trinta anos. Este o citou em "Psicologia das massas e análise do eu": "Pfister, em sua Frömmigkeit des Grafen von Zinzendorf, forneceu um exemplo extremamente claro e certamente não isolado de quão facilmente até um intenso vínculo religioso pode converter-se em ardente excitação sexual" (Freud, 1921/1996d, p. 150). 
como analogia da relação entre humano e divino não a partir da perspectiva sexual, mas da posição feminina.

A dimensão materna, por outro lado, provocou a desconfiança de que os fenômenos místicos, mesmo sendo considerados nas tradições religiosas como índices de maturidade humana e espiritual, seriam regressões aos estágios míticos mais recônditos da constituição subjetiva, nos quais reinaria a indiferenciação entre o Eu e a mãe, o que localizaria a mística no campo da psicose. $^{5}$

É inegável que muitos delírios paranoicos apresentam uma temática religiosa e que os psicóticos frequentemente se referem a Deus como representante de uma aspiração desmedida à totalidade. Este foi o caso de Daniel Paul Schreber (1903/1985), cujo delírio místico-religioso descrito em sua autobiografia foi analisado pelo criador da psicanálise (Freud, 1911/1996a).

Ainda assim, parece ser possível diferenciar a experiência mística autêntica do surto psicótico. ${ }^{6}$ Araújo (2015) sublinha que é importante conhecer e considerar seriamente as suspeitas à experiência mística, mas sustenta a possibilidade de indicar "critérios satisfatórios para identificar o verdadeiro misticismo, o que nos impede de descartar as vivências místicas como fenômenos puramente patológicos" (p. 62). Dentre os elementos apontados para um diagnóstico diferencial entre mística e psicose, destacamos aquele referente à relação do sujeito com o gozo. ${ }^{7}$

${ }^{5}$ Ferdinand Morel, Otto Rank e Franz Alexander sustentaram esta posição (cf. Araújo, 2015). Catherine Clément e Sudhir Kakar (1997) parecem admitir a mesma opinião quando aproximam as experiências de Madeleine e Ramakrishna, tendo sido a primeira internada como louca, na França, e o segundo aclamado como santo, na Índia.

${ }^{6} \mathrm{O}$ padre carmelita Bruno de Jésus-Marie, o filósofo Henri Bergson, a psicanalista Catherine Parat e o jesuíta Carlos Domínguez Morano sustentam uma posição semelhante (cf. Araújo, 2015). No artigo "A voz na habitação linguageira: o presidente e o cabalista", Frédéric Vinot (2018) traça um contraponto interessante entre a cabala judaica e o delírio schreberiano: enquanto na doutrina do Tzimtzum, proposta por Isaac de Luria, a retirada inicial de Deus de sua própria criação seria condição de possibilidade para tornar o mundo habitável para a criatura, no caso de Schreber a experiência da ausência de Deus é catastrófica e insuportável, provocando o horror no corpo do sujeito.

${ }^{7}$ Várias outras indicações preciosas são feitas para favorecer um diagnóstico diferencial entre o místico e o psicótico, às quais remetemos o leitor que desejar se aprofundar na matéria. 


\section{ARTIGOS}

Nos casos de psicose, a relação com o gozo é de aniquilamento subjetivo, na medida em que o surto psicótico impõe-se de maneira invasiva e incontrolável, que leva o psicótico a se referir a Deus como Outro não castrado ao qual se encontra subjugado. Trata-se, portanto, de uma dimensão que ultrapassa o assujeitamento próprio da dimensão alienante da constituição subjetiva. Nos casos em que a experiência mística se afigura como um indicativo que se aproxima do que Lacan supõe ser o gozo feminino, no qual a tônica da entrega de si é central, a relação com o gozo é de dessubjetivação, pois a experiência é desejada por quem a ela se dispõe, dedicando-se à meditação e à oração para buscar ativamente uma maior intimidade com Deus como Outro radical, e encontrar um lugar de acolhimento nessa alteridade, o que traz uma dimensão de júbilo e comunhão, sobre a qual é preciso testemunhar singularmente.

As narrativas místicas mostram que essa experiência pode vir a trazer efeitos subjetivantes quando o sujeito se apropria dela, vivenciando-a como uma entrega, e organiza um discurso em nome próprio para testemunhar os efeitos que experienciou. Trata-se, no entanto, de um momento a posteriori, só depois, uma vez que escrever sobre a experiência tem uma implicação fálica, em que o sujeito retorna ao campo sexual, da afirmação de si.

\section{Lacan e a mística}

Na abertura de seu Seminário 1 - Os escritos técnicos de Freud, Lacan (1953-54/2009) faz uma referência à mística zen: "O mestre interrompe o silêncio com qualquer coisa, um sarcasmo, um pontapé. É assim que procede, na procura do sentido, um mestre budista, segundo a técnica zen. Cabe aos alunos, eles mesmos, procurar a resposta às suas próprias questões" (p. 9).

Dois anos depois, no Seminário 3, As psicoses, ele recorre à tradição cristã para sinalizar a diferença radical entre a psicose schreberiana e a mística sanjuanista: "Ora, não há absolutamente nada de comum entre a ênfase que nos é dada de um lado e do outro. Eu diria mesmo que, a respeito do menor testemunho de uma experiência religiosa autêntica, vocês verão toda a diferença" (Lacan, 1955-56/2008b, p. 96).

Assim, na contramão das tendências nos campos psicológico, psiquiátrico e psicanalítico de classificar as experiências místicas como sintomas histéricos ou fenômenos psicóticos, Lacan inaugura uma nova 
maneira de abordá-las. Retomando a questão no Seminário 20, Mais, ainda, ele se refere à mística como "algo de sério, sobre o qual nos informam algumas pessoas, e mais frequentemente mulheres, ou bem gente dotada como São João da Cruz" (Lacan, 1972-73/2008b, p. 81). Para Lacan, esses sujeitos "experimentam a ideia de que deve haver um gozo que esteja mais além"; ele conclui: "É isto que chamamos os místicos" (p. 82).

Nesse momento de seu ensino, na década de 1970, Lacan se refere à experiência de Deus não mais predominantemente no registro Simbólico do Nome-do-Pai - como privilegiara na década de 1950, abordando a questão da presença de Deus no discurso (Lacan, 1953-54/2009, p. 153) - mas no registro Real, em referência ao campo do feminino como um acontecimento no corpo. ${ }^{8}$ Acompanhando os desenvolvimentos da teoria freudiana sobre a feminilidade e a sexualidade feminina e interrogando em que consiste a dimensão enigmática do dark continent (Freud, 1926/2017a, p. 240), o continente negro que seria habitado pelas mulheres, o mestre parisiense elaborou de maneira inédita a hipótese de um gozo Outro, fora do sexo, não fragmentado pela secção sexual, nomeado por ele de gozo feminino, no qual se frui não da afirmação viril, fálica, de si mesmo, mas sim da experiência 446 de dessubjetivação. Daí sua natureza hipotética, já que é uma experiência que se dá malgrado o sujeito, que incide fora do campo da representação. Nela, o sujeito está retirado e pode apenas pressenti-la como um acontecimento, e não como um ato de vontade.

A posição feminina se encontra de alguma maneira relacionada ao fim de análise, na medida em que se refere a uma "suplementação que se impõe frente à limitação do universo fálico da representação, no qual o sentido nunca é suficiente para dar conta da vida" (Maurano, 2006, p. 51). O campo do feminino "vincula-se a certo acolhimento do mistério, de um vazio prenhe de fecundidade, acolhimento da privação, para além da castração", atestando uma "operação real de elaboração de um luto do objeto, que não é senão luto de nosso atrelamento narcísico ao objeto fálico, com o qual tentamos sustentar

${ }^{8}$ Vale destacar, contudo, que já na década de 1950 ele se refere à suposição de que "Deus entre no discurso" como um "prolongamento da teoria do simbólico, do imaginário e do real" (Lacan, 1953-54/2009, p. 153), indicação que nos faz levantar a hipótese de que, tal como ocorre com toda experiência psíquica investigada à luz da teoria borromeana de Lacan, também as narrativas das experiências subjetivas com a divindade possam ser abordadas a partir de cada um dos registros R.S.I. 


\section{ARTIGOS}

a magnitude do Outro, como se isso nos garantisse alguma coisa". Portanto, "a desistência disso implica, por um lado, desasseguramento, mas, por outro, ampliação de horizontes" (p. 53).

A questão do término da análise se coloca como problemática na teorização de Freud, dado que este encontra no rochedo da castração um modo de designação de um limite para o sujeito na transposição de sua vinculação narcísica ao falo, o que torna portanto a análise contingente a esse limite (cf. Freud, 1937/2017b). Na teorização de Lacan, encontramos um modo de ampliação do percurso analítico através de sua incursão no campo do feminino, na medida em que ele propõe concebê-lo como um gozo suplementar, apresentando uma possibilidade de abordagem que responde não propriamente à castração, mas à privação, na qual a fruição se faz possível, malgrado a ausência do objeto. Deste modo, na gestão do gozo, seria possível aceder a um gozo Outro. Pensamos que é desse modo que a questão da dessubjetivação relativa à temática do fim de análise, para Lacan, pode indicar um passo além do rochedo da castração e um modo de operar no campo do gozo, ultrapassando o campo do desejo. ${ }^{9}$

A experiência de dessubjetivação pode ter como efeito uma nova modalidade de laço com a alteridade, avizinhando-se da dimensão mística, aliança com o infinito, com o ilimitado, com o Real incognoscível, mas que não deixa de relançar o sujeito no laço social, não raramente reconfigurando profundamente sua inserção sociopolítica. ${ }^{10} \mathrm{~A}$ despeito desta incognoscibilidade, suas incidências provocam efeitos, convocando cada sujeito a reconstruir sua realidade psíquica, tecendo articulações Simbólico-Imaginárias que lhe permitam manter uma distância "suficientemente boa" do Real — para

${ }^{9}$ Para um desenvolvimento mais abrangente das complexas articulações entre as experiências de dessubjetivação e de fim de análise, remetemos os leitores às obras A face oculta do amor: a tragédia à luz da psicanálise (Maurano, 2001) e Torções: a psicanálise, o barroco e o Brasil (Maurano, 2011).

${ }^{10}$ Sobre a relação entre mística e política, consultar a obra Mística e política, organizada por Maria Clara Lucchetti Bingemer e Roberto dos Santos Bartholo Jr. (1994). Como testemunho da íntima conexão entre essas esferas, vivenciada por um místico contemporâneo, recomendamos a leitura da obra Thomas Merton: contemplação no tempo e na história, de Sibélius Pereira (2014), na qual se torna evidente a estreita relação entre a experiência mística desse monge cisterciense e sua apaixonada defesa da não violência ativa, do diálogo inter-religioso e da superação do racismo. 
tomar de empréstimo a consagrada expressão do psicanalista inglês Donald Winnicott, que deixa entrever a saudável alternância entre proximidade e distância que a mãe precisará desenvolver em relação ao seu bebê (Winnicott, 1951/1978).

Mas é importante sublinhar que a experiência do gozo Outro só pode se dar quando o sujeito se constitui de modo a funcionar psiquicamente a partir do enodamento dos registros Real, Simbólico e Imaginário de suas experiências, ou seja, é fundamental que o complexo de Édipo, como estrutura complexa que organiza a experiência subjetiva que compõe a arquitetura do sujeito, tenha cumprido sua função de mapear o mundo, para que o sujeito possa nele tomar uma posição, ainda que seja para prescindir pontualmente das "coordenadas edípicas" (Brousse, 2012, p. 35), como na experiência jubilatória do gozo Outro.

Quando isso não ocorre e o complexo de Édipo não logra instituir o Nome-do-Pai como significante que estrutura o psiquismo, o que a irrupção do Real na cena psíquica promove é uma intrusão abusiva e devastadora do gozo do Outro, engendrando não propriamente uma dessubjetivação, mas uma anulação subjetiva, da qual o surto psicótico constitui o exemplo mais impactante, como atesta a autobiografia do presidente Schreber (1903/1985).

Embora o gozo do Outro compareça de modo devastador na psicose, isso não significa que, nas outras estruturas, não possa ser desencadeado em momentos pontuais de devastação subjetiva. A experiência do gozo do Outro, então, não surge em nada como júbilo ou celebração, mas, ao contrário, como angústia de aniquilamento e devastação. O Outro nessa experiência está longe de ser referência Simbólica à qual o sujeito está remetido, mas configura-se como potência Real, com todo o peso do aniquilamento subjetivo. Vejamos como essa questão foi elaborada no ensino de Lacan.

\section{Gozo do Outro e gozo Outro}

A diferença apontada por Lacan entre Schreber e São João da Cruz nos parece paradigmática para a proposta que tratamos de traçar: uma possível diferença entre gozo do Outro e gozo Outro. Enquanto Schreber, em seu surto psicótico, atribui a Deus a intrusão abusiva do Outro, que sem consultá-lo o emascula, torna-o sua mulher, São João da Cruz se refere a um casamento com Deus, celebrado com júbilo e posteriormente tornado poesia.

Talvez possamos dizer que, na experiência angustiante e intrusiva da feminilização de Schreber, ele se encontra anulado subjetivamente, na 


\section{ARTIGOS}

posição de objeto do gozo do Outro. No caso de São João da Cruz, opera-se uma dessubjetivação de certo modo consentida, não propriamente resultado do desejo do sujeito, mas de uma entrega subjetiva, razão pela qual essa experiência é vivida como um gozo Outro, promotora de júbilo e celebrada no ato poético que lhe confere, com a escrita a posteriori de sua experiência, uma posição na ordem Simbólica.

A tábua da sexuação elaborada por Lacan explicita que cada sujeito toma posição no campo do gozo, situando-se privilegiadamente do lado masculino (à esquerda) ou feminino (à direita). O quadro a seguir (Figura 1), formulado a partir daquele construído por Lacan, ilustra a diferenciação que propomos entre gozo Outro e gozo do Outro.



Figura 1: Tábua da sexuação de Jacques Lacan, aqui modificada conforme proposta de

Denise Maurano apresentada neste artigo (cf. Lacan, 1972-73/2008a, p. 84)b

No quarto superior esquerdo do quadro, no lado dos homens, ele formaliza a ideia de que, afora o pai totêmico, proposto por Freud (1913[1912-1913]/1996b) como hipótese para a origem mítica da cultura e do sujeito, que tinha pleno poder, todos os outros homens são condicionados pela função fálica, que impõe o limite do que a psicanálise nomeia como castração, marcando que todos estão "a menos" em relação ao falo. A exceção impôs a regra, que vale para todos, homens e mulheres, enquanto seres falantes, submetidos à linguagem.

No quarto superior direito, no lado das mulheres, Lacan indica a experiência de uma privação radical que revela que não há mulher que não 
tenha sido submetida à função fálica da castração, ou seja, nesse contexto no qual não há exceção, não se pode então formular uma regra. Com isso se quer dizer que, embora a função da castração participe de toda mulher, ela não está toda submetida a essa função, razão pela qual não é a totalidade dela que se inscreve na função fálica da castração, pois algo no feminino excede a essa função.

O gozo fálico se afigura como o vetor que parte de $\$$, sujeito dividido pela castração, e ultrapassa a linha de corte para o lado feminino, dirigindo-se ao objeto da fantasia inconsciente $(S \rightarrow a)$. Já o vetor que indica o gozo feminino não ultrapassa a linha de corte para o lado masculino e, portanto, situa-se como suplementar, fora da divisão sexual, fora-do-sexo [hors-sexe], como sugere Lacan, o que implica indicá-lo numa anterioridade lógica à partilha sexual, situá-lo antes da secção $(\mathrm{LA} \rightarrow \mathrm{S}(\mathrm{A}))$.

Desse modo, o gozo Outro, no qual situamos a experiência mística, não é relativo à relação de objeto, mas se refere, ao contrário, a um mais além do objeto e, portanto, mais além da fantasia. Tal experiência de comunhão com o infinito e com o ilimitado implica um preço a ser pago por essa entrega subjetiva: o preço da dessubjetivação, de certa ausência de delimitação, com todos os riscos e todo o júbilo que isso comporta. O que nela se afirma não é o apelo à conjunção com o objeto amado, mas o ultrapassamento de todo objeto.

Ainda no lado feminino, no qual o vetor não ultrapassaria a linha de corte para o lado masculino, sugerimos também incluir outro vetor, que parte desse limite da representação que caracteriza o feminino, em sua íntima relação com o Real, até o significante do Outro não barrado, formalizando com isso a experiência, não do gozo Outro, mas do gozo do Outro $(\mathrm{LA} \rightarrow \mathrm{S}(\mathrm{A}))$. Mesmo que não haja uma diferenciação precisa de Lacan acerca dessa distinção, parece-nos que suas indicações tornam esse acréscimo não somente possível, mas também pertinente.

Com a nossa inclusão de outro vetor na tábua da sexuação, com o qual sugerimos caracterizar o gozo do Outro, aniquilador, cujo expoente comparece no surto psicótico, queremos demarcar também a relação da psicose com a posição feminina, indicada por Lacan através do que teoriza como empuxo à mulher. É interessante observar com isso que não se trata de isentar o psicótico de sua inclusão na dialética sexual, mas de apresentá-la na sua problemática específica, na qual, devido à fragilidade de sua inscrição subjetiva na divisão dos sexos, como uma das consequências da foraclusão do Nome-do-Pai, busca indicar o assombramento relativo a um apassivamento, não jubilatório, mas aniquilante, devastador. 


\section{ARTIGOS}

\section{Considerações finais}

Por fim, podemos considerar que, como tudo o que constitui o campo da teoria analítica, também a abordagem lacaniana da mística se encontra de alguma maneira em referência à clínica. Oferecendo elementos que nos permitem reconhecer uma clara oposição à patologização da experiência mística, Lacan indica uma íntima conexão entre o avanço do tratamento analítico e a conquista de uma abertura ao campo do feminino. O sujeito em análise, ao percorrer uma longa travessia de sua própria fantasia inconsciente, constata que essa construção Simbólico-Imaginária não é apenas uma tela, mas também uma janela para o Real: "A experiência analítica, centrada para Lacan na travessia da fantasia, representa, no fundo, a possibilidade de expansão desses moldes excessivamente rígidos, por meio dos quais o sujeito constitui sua relação com o mundo" (Jorge, 2011, p. 153). Essa experiência de despertar aproxima o místico do psicanalista, como insinuou Lacan, pois ambos constatam que a garantia narcísica aportada pelo falo é furada, ao se depararem com a verdade de que seu eu não é o senhor de sua própria casa (Freud, 1917/1996c, p. 153).

Agradecimentos: Coordenação de Aperfeiçoamento de Pessoal de Nível Superior - CAPES, Corpo Freudiano Escola de Psicanálise e grupo de pesquisa Apophatiké: estudos interdisciplinares em mística (UFF/PUC-Rio)

\section{Referências}

Albuquerque, B. (2018). Mística e psicanálise: uma introdução, de Freud a Lacan. Psicanálise \& Barroco em Revista, 16(1), 213-219. Recuperado em 20 mar. 2019 de: <http://www.seer.unirio.br/index.php/psicanalise-barroco/article/ viewFile/7963/6896>.

Araújo, R. T. de. (2015). Experiência mística e psicanálise. São Paulo, SP: Loyola.

Araújo, R. T. de. Mística e psicanálise. Theologica Latinoamericana-Enciclopédia Digital. Recuperado em 20 mar. 2019 de: <http://theologicalatinoamericana. $\mathrm{com} / \mathrm{p}=1549>$.

Bíblia (2010). Português. Bíblia de Jerusalém. São Paulo, SP: Paulus.

Bingemer, M. C. L., \& Bartholo Jr., R. dos S. (Orgs.). (1994). Mística e política. São Paulo, SP: Loyola. (Coleção Seminários Especiais - Centro João XXIII, 9).

Brousse, M.-H. (2012, jun.). O que é uma mulher. Latusa digital, 9(49). Recuperado 
em 25 abr. 2016 de: <http://www.latusa.com.br/pdf_latusa_digital_49_a1.pdf>. Clément, C., \& Kakar, S. (1997). A louca e o santo. Rio de Janeiro, RJ: Relume-Dumará.

Domínguez Morano, C. (2016). El “Otro” de los místicos: reflexiones desde el psicoanálisis - Discurso inaugural del curso acadêmico 2016-2017. Facultad de Teología de Granada.

Freud, S., \& Breuer, J. (1996). Estudos sobre a histeria. In Edição Standard Brasileira das Obras Psicológicas Completas de Sigmund Freud (ESB) (v. II, pp. 11-319). Rio de Janeiro, RJ: Imago. (Trabalho original publicado em 1893-1895).

Freud, S. (1996a). Notas psicanalíticas sobre um relato autobiográfico de um caso de paranoia. In Edição Standard Brasileira das Obras Psicológicas Completas de Sigmund Freud (ESB) (v. XII, pp.13-89). Rio de Janeiro, RJ: Imago. (Trabalho original publicado em 1911).

Freud, S. (1996b). Totem e tabu: alguns pontos de concordância entre a vida mental dos selvagens e dos neuróticos. In Edição Standard Brasileira das Obras Psicológicas Completas de Sigmund Freud (ESB) (v. XIII, pp. 11-163). Rio de Janeiro, RJ: Imago. (Trabalho original publicado em 1913[1912-1913]).

Freud, S. (1996c). Uma dificuldade no caminho da psicanálise. In Edição Standard Brasileira das Obras Psicológicas Completas de Sigmund Freud (ESB) (v. XVII, pp. 143-153). Rio de Janeiro, RJ: Imago. (Trabalho original publicado em 1917).

Freud, S. (1996d). Psicologia de grupo e análise do ego. In Edição Standard Brasileira das Obras Psicológicas Completas de Sigmund Freud (ESB) (v. XVIII, pp. 77-154). Rio de Janeiro, RJ: Imago. (Trabalho original publicado em 1921).

Freud, S. (1996e). O mal-estar na civilização. In Edição Standard Brasileira das Obras Psicológicas Completas de Sigmund Freud (ESB) (v. XXI, pp. 65-148). Rio de Janeiro, RJ: Imago. (Trabalho original publicado em 1930[1929]).

Freud, S. (1996f). Achados, ideias, problemas. In Edição Standard Brasileira das Obras Psicológicas Completas de Sigmund Freud (ESB) (v. XXIII, pp. 317-318). Rio de Janeiro, RJ: Imago. (Trabalho original publicado em 1941[1938]).

Freud, S. (2017a). A questão da análise leiga. Conversas com uma pessoa imparcial. In Fundamentos da clínica psicanalítica (pp. 205-313). Belo Horizonte, MG: Autêntica. (Trabalho original publicado em 1926). (Obras incompletas de Sigmund Freud, 6).

Freud, S. (2017b). A análise finita e a infinita. In Fundamentos da clínica psicanalitica (pp. 315-364). Belo Horizonte, MG: Autêntica. (Trabalho original publicado em 1937). (Obras incompletas de Sigmund Freud, 6).

Fuks, B. (2000). Freud e a judeidade: a vocação do exílio. Rio de Janeiro, RJ: Zahar. 


\section{ARTIGOS}

James, W. (1995). As variedades da experiência religiosa: um estudo sobre a natureza humana. São Paulo, SP: Cultrix. (Trabalho original publicado em 1902).

João da Cruz, São (2013). Noite escura (5ª ed.). Petrópolis, RJ: Vozes.

Jorge, M. A. C. (2011). O desejo de despertar. In D. Maurano, H., \& Neri, M. A. C. Jorge (Orgs.), Dimensões do despertar na psicanálise e na cultura (pp. 151-162). Rio de Janeiro, RJ: Contra Capa Livraria/Corpo Freudiano Seção Rio de Janeiro.

Lacan, J. (2008a). O seminário. Livro 3. As psicoses (2a ed.). Rio de Janeiro, RJ: Zahar. (Trabalho original publicado em 1955-56).

Lacan, J. (2008b). O seminário. Livro 20. Mais, ainda. Rio de Janeiro, RJ: Zahar. (Trabalho original publicado em 1972-73).

Lacan, J. (2009). O seminário. Livro 1. Os escritos técnicos de Freud (2a ed.). Rio de Janeiro, RJ: Zahar. (Trabalho original publicado em 1953-54).

Maurano, D. (2001). A face oculta do amor: a tragédia à luz da psicanálise. Rio de Janeiro, RJ/Juiz de Fora, MG: Imago/Editora UFJF.

Maurano, D. (2006). A transferência: uma viagem rumo ao continente negro. Rio de Janeiro, RJ: Zahar.

Maurano, D. (2011). Torções: a psicanálise, o barroco e o Brasil. Curitiba, PR: CRV.

Pereira, S. (2014). Thomas Merton: contemplação no tempo e na história. São Paulo, SP: Paulus.

Pfister, O. (1910). Die Frömmigkeit des Grafen Ludwig von Zinzendorf: ein psychoanalytischer Beitrag zur Kenntnis der Religiösen Sublimierungsprozesse und zur Erklärung des Pietismus. Leipzig/Viena: Franz Deuticke.

Schreber, D. P. (1985). Memórias de um doente dos nervos [traduzido do original alemão e organizado por Marilene Carone] (2 $2^{\text {a }}$ ed.). Rio de Janeiro, RJ: Graal. (Trabalho original publicado em 1903).

Terêncio, M. G. (2011). Um percurso psicanalítico pela mística, de Freud a Lacan. Florianópolis, SC: Editora da UFSC.

Teresa d'Ávila, Santa. Textos selecionados. In M. C. L. Bingemer, \& M. R. Pinheiro (Orgs.) (2016), Narrativas místicas: antologia de textos místicos da história do cristianismo (pp. 228-236). São Paulo, SP: Paulus. (Coleção Amantes do Mistério).

Vergote, A. (1978). Dette et désir: deux axes chrétiens et la derive pathologique. Paris, França: Seuil.

Vinot, F. (2018). A voz na habitação linguageira: o presidente e o cabalista. In S. M. de S. Levy, \& M. F. P. Dias (Orgs.), A céu aberto: o inconsciente na clínica das psicoses (pp. 185-192). Rio de Janeiro, RJ: Contra Capa/Corpo Freudiano Seção Belém. 
Winnicott, D. (1978). Objetos transicionais e fenômenos transicionais. In Textos selecionados: da pediatria à psicanálise (pp. 389-408). Rio de Janeiro, RJ: Francisco Alves. (Trabalho original publicado em 1951).

\section{Resumos}

(Lacan and the mystical experience in the light of psychoanalysis)

This paper describes in what way Jacques Lacan opens a new path to approach the mystical experience in the light of psychoanalysis. The French master compares the path of the analyst to the one undertaken by the mystic and thus goes against the trends in the fields of psychology, psychiatry and psychoanalysis that pathologized this phenomenon at that time and reduced it to hysterical or psychotic symptomatology. Lacan also draws an intimate connection between the goal of the analysis and the achievement of an opening to the feminine field. Following the path suggested by this author, we suggest distinguishing the notions of Other jouissance and jouissance of the Other, providing elements for a differential diagnosis between mystical experience (marked by desubjectification) and psychotic outbreak (marked by subjective annihilation).

Key words: Jacques Lacan, mystical experience, psychoanalysis, jouissance

(Lacan et l'expérience mystique à la lumière de la psychanalyse)

Cet article présente la façon par laquelle Jacques Lacan inaugure une nouvelle façon d'aborder l'expérience mystique à la lumière de la psychanalyse. Contrairement aux tendances du domaine de la psychologie, de la psychiatrie et de la psychanalyse qui pathologise ce phénomène, le réduisant à une symptomatologie hystérique ou psychotique, le maître français rapproche le parcours de l'analyste à celui du mystique, établissant un lien intime entre le but de l'analyse et la conquête d'une ouverture au champ du féminin. Suivant la ligne établie par cet auteur, nous proposons de différencier les notions de jouissance Autre et jouissance de l'Autre, indiquant des éléments qui permettent d'établir un diagnostic différentiel entre l'expérience mystique (marquée par la désubjectivation) et le déclenchement psychotique (marqué par l'annihilation subjective).

Mots clés: Jacques Lacan, expérience mystique, psychanalyse, jouissance

(Lacan y la experiencia mística a la luz del psicoanálisis)

El presente artículo presenta la forma en la que Jacques Lacan inaugura una nueva manera de abordar la experiencia mística a la luz del psicoanálisis. En contraste con las tendencias en el campo de la psicología, de la psiquiatría y 


\section{ARTIGOS}

del psicoanálisis de patologizar este fenómeno, reduciéndolo a la sintomatología histérica o psicótica, el maestro francés acerca el recorrido del analista a aquel emprendido por el místico, trazando una íntima conexión entre el fin del análisis y la conquista de una apertura hacia el campo de lo femenino. En los caminos abiertos por este autor, proponemos diferenciar las nociones de goce Otro y goce del Otro, enseñando elementos para un diagnóstico diferencial entre experiencia mística (marcada por la desubjetivación) y brote psicótico (marcado por el aniquilamiento subjetivo).

Palabras clave: Jacques Lacan, experiencia mística, psicoanálisis, goce

\section{(Lacan und die mystische Erfahrung im Licht der Psychoanalyse)}

Dieser Artikel beschreibt wie Jacques Lacan einen neuen Ansatz entwickelt, um die mystische Erfahrung im Licht der Psychoanalyse anzugehen. Er verwirft die damals in der Psychologie, Psychiatrie und Psychoanalyse bestehenden Tendenzen, die dieses Phänomen pathologisieren und auf eine hysterische oder psychotische Symptomatologie beschränken und nähert die Vorgehensweise des Analytikers an die des Mystikers an, wobei er eine enge Verbindung zwischen dem Ziel der Analyse und dem Erreichen einer Öffnung des Weiblichen Feldes herstellt. In Übereinstimmung mit der von diesem Autor entwickelten Linie schlagen wir vor, die Begriffe „Anderes Genießen " und „Genießen des Anderen" zu unterscheiden und bieten Elemente an, die zur Erstellung einer Diagnose beitragen, welche zwischen der (von der Entsubjektivierung geprägten) mystischen Erfahrung und dem (von der subjektiven Annihilation geprägten) psychotischen Ausbruch unterscheidet.

Schlüsselwörter: Jacques Lacan, mystische Erfahrung, Psychoanalyse, Genießen

Citação/Citation: Maurano, D., \& Albuquerque, B. (2019, setembro). Lacan e a experiência mística à luz da psicanálise. Revista Latinoamericana de Psicopatologia Fundamental, 22(3), 439-456. http://dx.doi.org/10.1590/1415-4714.2019v22n3p439.3.

Editora/Editor: Profa. Dra. Sonia Leite

Submetido/Submitted: 15.4.2019 / 4.15.2019 Versão revisada/Revised Date: 18.6.2019 / 6.18.2019

Aceito/Acepted: $19.6 .2019 / 6.19 .2019$

Copyright: (C) 2009 Associação Universitária de Pesquisa em Psicopatologia Fundamental/ University Association for Research in Fundamental Psychopathology. Este é um artigo de livre acesso, que permite uso irrestrito, distribuição e reprodução em qualquer meio, desde que o autor e a fonte sejam citados / This is an open-access article, which permits unrestricted use, distribution, and reproduction in any medium, provided the original authors and sources are credited. 
Financiamento/Funding: Este trabalho conta com o apoio da Coordenação de Aperfeiçoamento de Pessoal de Nível Superior - CAPES (Brasília, DF, Br) / This work was supported by the Coordenação de Aperfeiçoamento de Pessoal de Nível Superior - CAPES (Brasília, $\mathrm{DF}, \mathrm{Br})$.

Conflito de interesses/Conflict of interest: Os autores declaram que não há conflito de interesses / The authors declare that there is no conflict of interest.

\section{Denise Maurano}

Doutora em Filosofia pela Universidade Paris XII (Paris, França)/Pontifícia Universidade Católica do Rio de Janeiro - PUC-Rio (Rio de Janeiro, RJ, Br), com estágio pós-doutoral em Letras pela PUC-Rio; Professora titular do Programa de Pós-Graduação em Memória Social e da Escola de Direito da Universidade Federal do Rio de Janeiro - Unirio (Rio de Janeiro, RJ, Br); Editora de Psicanálise \& Barroco em Revista: www.psicanaliseebarroco. pro.br/revista; Psicanalista membro do Corpo Freudiano Escola de Psicanálise - Seção Rio de Janeiro (Rio de Janeiro, RJ, Br).

Rua Hermenegildo de Barros, 27 - Santa Teresa

20241-040 Rio de Janeiro, RJ, Br dmaurano@corpofreudiano.com.br.

https://orcid.org/0000-0003-3498-3773

\section{Bruno Albuquerque}

Doutorando em Ciência da Religião na Universidade Federal de Juiz de Fora - UFJF (Juiz de Fora, MG, Br); Bolsista da Coordenação de Aperfeiçoamento de Pessoal de Nível Superior - CAPES (Brasília, DF, Br); Mestre em Psicanálise pela Universidade do Estado do Rio de Janeiro - UERJ (Rio de Janeiro, RJ, Br); Psicólogo pela UERJ; Membro da International Association for the Psychology of Religion - IAPR (Nuremberg, Germany); Integrante dos grupos de pesquisa Apophatiké: estudos interdisciplinares em mística (UFF/PUC-Rio) e NERELPSI: Núcleo de Estudos Religião e Psique (UFJF); Membro associado do Corpo Freudiano Escola de Psicanálise - Seção Rio de Janeiro (Rio de Janeiro, RJ, Br).

Rua Hermenegildo de Barros, 27, Santa Teresa

20241-040 Rio de Janeiro, RJ, Br brunopintodealbuquerque@gmail.com. https://orcid.org/0000-0003-4495-2444

\section{(cc) BY-NC}

This is an open-access article, which permits unrestricted use, distribution, and reproduction in any medium for non-commercial purposes provided the original authors and sources are credited. 